\title{
Moeten universiteiten moreel opvoeden?
}

\section{Een samenvattende persoonlijke reflectie bij het zesde Ethisch Forum van de Universitaire Stichting \\ Philippe Van Parijs*}

Het is uiteraard de taak van een universiteit om haar studenten de professionele vaardigheden aan te leren die nodig zijn op de arbeidsmark.t. Misschien behoort het ook tot haar taak om de kritische houding die een bloeiende democratie nodig heeft, aan te leren. Maar is het ook haar taak om studenten de ethische waarden te leren die bun professionele leven zouden moeten bepalen - of dat nu is als dokters, ingenieurs, managers, advocaten, leerkrachten, journalisten of in een ander beroep?

Zo ja, hoe moet dat gebeuren? Door het aanleren van deontologische codes voor de beroepen die studenten waarschijnlijk gaan uitoefenen? Door een bepaalde positie te verdedigen in gevalsstudies? Door het goede voorbeeld te geven?

Zo neen, betekent dit een capitulatie voor de dictaten van de markt? Wat blijft er dan over van de waarden die zogenaamd de identiteit van sommige universiteiten bepalen en die vol vuur ingeroepen worden in hun beginselverklaringen, op bun websites en in hun meest plechtige ceremonieën? Alleen lege retoriek, irrelevant voor het toekomstige professionele gedrag van studenten, misschien zelfs schaamteloos hypocriet?

Dit zijn de vragen die voorgelegd werden aan de sprekers en deelnemers van het zesde Ethisch Forum van de Universitaire Stichting, met het verzoek om direct de moeilijke en delicate kwesties aan te pakken. Niet gemakkelijk, zo bleek. En nog minder gemakkelijk om de inzichten die ik daar opdeed helder samen te vatten. Hier volgt een poging. ${ }^{1}$

\section{Het vrije onderzoek als de ethiek van het zoeken naar de waarbeid}

Op de vraag welke waarden universiteiten mogen en moeten doorgeven aan hun studenten, bleek al snel één antwoord unaniem onderschreven te worden. Een

* Philippe Van Parijs is gewoon hoogleraar en hoofd van de Hoover Leerstoel in economische en sociale ethiek aan de Université Catholique de Louvain in Louvain-la-Neuve, bijzonder gasthoogleraar aan het Hoger Instituut voor Wijsbegeerte van de K.U.Leuven en het Department of Philosophy van Harvard University, en coördinator van het Ethisch Forum.

E-mail: pvp@uclouvain.be 


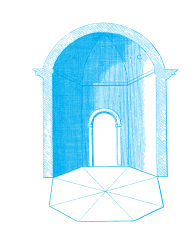

universiteit draait vooral rond de overdracht van wat we beschouwen als 'ware kennis', voor velen van ons gecombineerd met onderzoek, dus met de poging om nog meer ware kennis te genereren. Deze onderneming kan niet slagen zonder een engagement voor het ongeremde zoeken naar de waarheid, ook als die ingaat tegen onze individuele of collectieve belangen, onze conventies en vooroordelen of een extern opgelegde autoriteit, of die nu religieus of seculier is. Het vrije onderzoek verwijst in zijn enge interpretatie precies naar dit waarde-engagement. De kritiek op het Leuvense falen om dit engagement na te leven speelde een centrale rol in de oprichting van de Université Libre de Belgique (later de Université Libre de Bruxelles en nog later de ULB/VUB) door negentiende-eeuwse liberalen - ironisch genoeg in het Hotel Granvelle, het paleis van de eerste aartsbisschop van Mechelen-Brussel - en in de manier waarop haar erfgenamen hun specifieke identiteit zijn blijven bepalen sindsdien.

$\mathrm{Er}$ is absoluut niets passé aan dit engagement. Integendeel, in plaats van de eigenheid van één van onze universiteiten is het nu de consensus die hen allemaal samenbrengt. Zoals professor in de fysica Jean Bricmont van de UCL het stelt: "Het katholicisme heeft zich niet geopend voor het secularisme, het is erdoor overwonnen, wat iets heel anders is. Om het devies van de ULB te herhalen, de wetenschap heeft het duister overwonnen, tenminste in België en vandaag. Een bescheiden triomf is altijd beter, maar je mag daarom winnaars en overwonnenen niet verwisselen." ${ }^{2}$ Dit klinkt nogal bot, maar is niet fundamenteel verschillend van wat de eerste rector van de K.U.Leuven, Pieter De Somer, kort voor zijn dood op een gedenkwaardige manier uitdrukte ter gelegenheid van het bezoek van paus Johannes Paulus II: "De Katholieke Universiteit Leuven heeft de plicht om overgeërfde waarheden constant in vraag te stellen en indien nodig aan te passen aan de moderne taal en het moderne denken... Wat hun vakgebied ook is, onderzoekers moeten de vrijheid hebben om dat onbekende in kaart te brengen, om werkhypotheses uit te breiden en te testen, om nieuwe bevindingen te integreren met wat al geweten is, om nieuwe conclusies te trekken over wat vooraf ging. Ze moeten ook het recht hebben om zich te vergissen. Dit is één van de meest essentiële voorwaarden, voor hen om hun functie als onderzoeker te kunnen uitoefenen en voor de universiteit om haar gepaste institutionele taak uit te voeren." ${ }^{3}$

Vrij onderzoek in deze betekenis is ongetwijfeld een waarde, een die we kunnen en zelfs moeten onderwijzen aan alle studenten die zelf onderzoek gaan doen, maar ook breder, aan al onze studenten, wat hun toekomstige loopbaan ook is, en zelfs aan iedereen waar we hopen invloed op te hebben. We zijn het uiteraard vaak oneens over wat de waarheid is, maar we zijn het er allemaal over eens dat we bij het confronteren van 
onze meningsverschillen alleen oog moeten hebben voor empirisch bewijs en logische gevolgtrekking, en dat we onszelf moeten afschermen voor de invloed van vooroordelen en externe autoriteiten. Op dit vlak willen we zeker niet terug naar de Europese universiteiten van de middeleeuwen, hoeveel we hen ook verschuldigd zijn, zoals terecht benadrukt werd door Andris Barblan. Integendeel, we willen de vrijheid van externe bemoeienis die we langzaam veroverd hebben, consolideren en bewaren. Die verovering was een belangrijk deel van misschien de meest roemrijke periode van ons universitair verleden, waarin het innovatieve humanisme dat aan de Universitas Lovaniensis heerste, kardinaal Granvelle ertoe bracht in Douai een andere universiteit te stichten die meer ontvankelijk was voor de dictaten van de inquisitie.

\section{Deontologie als beroepsethos}

Het vrije onderzoek vormt zo een eerste oncontroversiële waarde waarvan we voelen dat we die aan onze studenten kunnen en moeten aanleren. Eén aspect ervan is meer geformaliseerd dan de rest: de deontologie die we moeten onderwijzen aan de groep studenten die zelf aan wetenschappelijk onderzoek gaan doen. Als biochemicus vervals je de resultaten van je experimenten niet om interessante veronderstellingen te rechtvaardigen. Als historicus smuk je gebeurtenissen uit het verleden niet op om het prestige van je natie te vergroten.

De deontologie van het onderzoek is echter maar een klein deel van een tweede groep waarden die ontegensprekelijk tot de onderwijstaak van de universiteit horen. Dit zijn de waarden die belichaamd worden in de verschillende deontologische codes. We geven zonder probleem toe dat er in de opleiding van dokters, journalisten of juristen ruimte moet zijn voor de deontologische codes die specifiek horen bij de beroepen die ze waarschijnlijk gaan uitoefenen. Maar waarom zijn er codes voor sommige beroepen waar de universiteit op voorbereidt en niet voor andere? Een duidelijke asymmetrie in informatiebezit tussen de verleners van een - bijvoorbeeld juridische of medische - dienst en hun cliënten vormt zeker een deel van het verhaal. Waarschijnlijk ook het risico dat het uitoefenen van het beroep ten dienste van het welzijn van de 'consument' van die informatie of gezondheidszorg bemoeilijkt wordt door financiële druk - van adverteerders op journalisten, van farmaceuten op dokters. Om het vertrouwen in het beroep te bewaren, is het dus in het gemeenschappelijke belang van de beroepsuitoefenaars om zich te onderwerpen aan een beroepsdeontologie: een geheel van 'zachte wetgeving' dat soms indirect gesteund word door harde wetgeving, zoals wanneer het uitoefenen van een beroep wettelijk beperkt wordt 


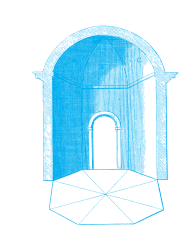

tot de leden van een professionele organisatie die de macht heeft om een deontologische code aan te nemen en iedereen die deze code niet naleeft uit te sluiten.

Zo gezien lijkt het aanleren van een deontologie dichter aan te leunen bij het aanleren van de wet dan het aanleren van morele waarden: een deontologische code is gewoon een reeks regels die, wat opstelling en oplegging betreft, door de wetgever zijn gedelegeerd aan gespecialiseerde instellingen die meer op de hoogte zijn van de problemen die moeten aangepakt worden en die waarschijnlijk ook meer bekwaam zijn om ze aan te pakken. Het aanleren van een deontologie kan echter niet gereduceerd worden tot het overbrengen van regels en de erbij behorende casuïstiek. Er is ook het belichten van bepaalde waarden die de kern uitmaken van het ethos van een bepaald beroep - denk bijvoorbeeld aan de onpartijdige verstrekking van informatie voor journalisten, of de gezondheid van de patiënt, vandaag de dag gecombineerd met de houdbaarheid van geïnstitutionaliseerde solidariteit, voor de medische en paramedische beroepen. En het aanleren van deontologie betekent ook de studenten in het licht van dit beroepsethos wijzen op dilemma's en compromissen die ze misschien gaan tegenkomen. Dit gaat verder dan het aanleren van een geheel van zachte wetgeving en brengt ons bij waarden, zoals de waarde van het beeld van een beroep dat je met trots goed zou uitoefenen. Een beeld dat je alleen tot je schaamte zou bezoedelen, bijvoorbeeld door lage interesses te laten overheersen of door op te gaan in technische virtuositeit en intussen te vergeten dat je met mensen bezig bent - niet alleen met dood vlees in de anatomieles, niet alleen met cijfers in de les boekhouding.

Managers 'sociale bedrijfsverantwoordelijkheid' leren past ook goed in dit patroon, ook al wordt dat niet vaak omschreven als 'managementdeontologie'. Zoals door Nigel Roome weergegeven werd, bestaat dit vaak uit studenten wijzen op de menselijke gevolgen van de beslissingen die managers moeten nemen in de loop van hun carrières, of dat nu routinematig is of in uitzonderlijke omstandigheden. Is er dan geen fundamenteel verschil tussen een utilitaristische en een deontologische aanpak? In deze context is het beroep doen op dit versleten onderscheid oppervlakkig en misleidend. Verstandige deontologieën werken vooral doordat ze de beroepsuitoefenaars verplichten om aandacht te hebben voor de gevolgen van hun gedrag, en de gevolgen van het veralgemenen van een specifiek gedragspatroon naar de hele beroepsgroep. Zelfs wanneer ze de vorm hebben van een reeks vuistregels of procedures om te volgen, passen alle deontologieën, of ze nu voor journalisten, dokters, juristen of managers zijn, uiteindelijk in een reflectie op hoe een beroep het beste een nuttige bijdrage kan bieden aan de maatschappij, en bijgevolg ook in een utilitaristisch kader. 


\section{Ethiekvakken als vakken in cultuur en redeneren}

Laten we samenvatten. Wat het onderwijzen van waarden betreft, horen gesubsidieerde $21^{\text {ste }}$-eeuwse universiteiten aan de ene kant het ethos van waarheid zoeken, dat intrinsiek is aan de wetenschappelijke kant van het academische beroep, te verspreiden. Aan de andere kant horen ze toekomstige beroepsmensen het ethos aan te leren dat de specifieke deontologie van hun beroepen onderbouwt, in het langetermijnbelang van zowel deze beroepen als de samenleving.

Naast deze twee manieren om waarden te onderwijzen, kunnen universiteiten ongetwijfeld ook vakken ethiek, moraal of politieke filosofie aanbieden, wat ze inderdaad op grote schaal en buiten hun filosofiecurricula doen. Zulke vakken zijn niet gericht op het aanleren van zogenaamde 'ware' waarden of inhoudelijke ethische visies die studenten moeten overnemen, maar eerder gericht op het onbevooroordeeld inleiden in het bestaande corpus van wat er op deze gebieden gedacht wordt - niet alleen een geschiedenis van de klassieken, maar ook huidige controverses - en op het aanleren hoe rigoureus te argumenteren over ethische zaken. Zowel de observatie van Emmanuelle Danblon dat onderzoek geen probleem oplevert op wetenschappelijk vlak maar dat het op filosofisch vlak het risico loopt dogmatisch en dus problematisch te worden, als de opmerking van Bart Pattyn dat universiteiten hun studenten geen particuliere ideologie zouden mogen onderwijzen, lijken een bekrachtiging van deze zelfbeperking tot een ethisch neutrale houding in het onderwijzen van ethiek.

\section{Universiteiten als waardevormende omgevingen}

Het zou gemakkelijk zijn als we hier konden stoppen. Maar twee aspecten van de discussies op het Ethisch Forum wijzen erop dat we dat niet kunnen doen. Ten eerste zijn er waarden die niet herleid kunnen worden tot het zoeken van de waarheid of een deontologie, en die onvermijdelijk, hoe onopvallend ook, sommige beslissingen van universiteitsautoriteiten sturen: beslissingen over wat er wel en niet gedaan en gezegd kan worden op de campus, waardoor ze tot op zekere hoogte vormgeven aan wat studenten als triviaal of problematisch zullen zien voor de rest van hun leven.

Sommige van deze keuzes worden gemaakt in de context van de onderwijsactiviteiten van de universiteit. Bijvoorbeeld het inrichten van een vak palliatieve zorg, tot voor kort een taboe onderwerp, of het adverteren van een interdisciplinair ecologisch programma met slagzinnen die onze verantwoordelijkheid naar toekomstige 


\section{(}

generaties benadrukken, kunnen niet echt waardeneutraal genoemd worden. Andere relevante keuzes functioneren op grotere afstand van onderwijsactiviteiten. Denk bijvoorbeeld aan het wat exotische geval van de door Jean-Pierre Richer beschreven christelijk fundamentalistische Bob Jones University in South Carolina, waar kleurlingen en blanken niet met elkaar mochten uitgaan op de campus. Of veel dichterbij, denk aan het verbod op plaatsen van eredienst aan één van onze universiteitscampussen, of aan het toewijzen van een universiteitspeda aan een project voor homostudenten in plaats van aan de plaatselijke tak van Opus Dei.

Door bepaalde activiteiten toe te laten, te verbieden, aan te moedigen of te ontmoedigen, is dit soort beslissingen nauwelijks neutraal in inspiratie en nog minder neutraal in impact op de normatieve overtuigingen van studenten. Natuurlijk kunnen sommige van deze maatregelen contraproductief blijken: discriminatie van Opus Dei kan tot bekeringen aanzetten en ecologisch hersenspoelen kan ecologische cynici opleveren. Maar we kunnen toch verwachten dat studenten die min of meer vlijtig gestudeerd hebben aan een instelling die bepaalde houdingen en gedragingen tolereert of bevordert en andere benadeelt, voor de rest van hun leven de neiging zullen hebben de eerste als vanzelfsprekend te zien en de laatste als problematisch. Binnen de grenzen van wat de wet oplegt en verbiedt, is er veel dat een universiteit en haar vele organen kunnen kiezen wel of niet te doen, toe te laten of te verbieden.

Toegegeven, de waarden die impliciet onderwezen worden door een dergelijke omgeving zijn geen volledig uitgewerkte rechtvaardigheidsconcepten of volledig ontwikkelde ideologieën. Ze zijn meestal ook van zo'n aard dat weinigen ze hier en nu openlijk in vraag zouden durven stellen. Maar dit betekent niet dat het geen waarden zijn of dat ze niet onderwezen worden aan en door onze universiteiten, of die dat nu willen erkennen of niet. Het onderwijzen van waarden is niet te herleiden tot het preken van waarden. Bijgevolg betekent het afzien van het preken van waarden in ethiekvakken niet dat universiteiten niet moeten nadenken over welke waarden ze aan hun studenten onderwijzen en zouden moeten onderwijzen door de brede omgeving die ze bij hun beslissingen scheppen.

\section{Universiteitsdocenten als oudere broers en zussen}

Dit toegeven is niet bepaald aangenaam. Maar het wordt nog erger. Zoals vooral door Andris Barblan benadrukt werd, is de pedagogische relatie tegelijkertijd en onlosmakelijk een overdracht van kennis (savoir), vaardigheden (savoir-faire) en savoirêtre, wat onvermijdelijk een morele dimensie inhoudt. Uiteraard kan elk van deze 
aspecten van de onderwijsfunctie inefficiënt uitgevoerd worden. Wat het derde aspect betreft: het is zeker ontnuchterend voor ons, universiteitsdocenten, dat toen enkele van onze UCL-studenten gevraagd werd van wie ze hun morele perspectief hadden, in hun antwoorden hun families, jeugdbewegingleiders en basisschoolleerkrachten veel prominenter naar voor kwamen dan wij. Nochtans hield de bewondering van velen van ons voor sommige van onze professoren ongetwijfeld verband met hun manier van zijn, en niet alleen met hoe grondig ze nadachten, hoeveel ze wisten en hoe briljant ze lesgaven.

Wat hieruit volgt, is toch een stuk algemener en radicaler dan alleen verwachten dat professoren van moraalfilosofie of politieke filosofie 'uit de kast komen' en bekennen wat hun eigen visies zijn, in plaats van alleen op te sommen wat anderen denken. Het is ook algemener en radicaler dan verwachten dat iedereen die vakken met beleidsrelevantie geeft, zijn nek uitsteekt en - op basis van expliciete waardeoordelen en van wat hij denkt te weten - aangeeft wat moet gedaan worden. ${ }^{4}$ Wat er nog veel algemener uit volgt, is dat universiteitsdocenten, samen met alle andere leerkrachten, er niet voor zouden mogen terugschrikken om 'oordelend' te zijn, om te stellen dat niet alles gelijkwaardig is. Aangezien er geen manier bestaat om de morele boodschap uit de onderwijsrelatie weg te werken, kan bewuste morele onthouding te gemakkelijk geïnterpreteerd worden als een engagement voor gelijkwaardigheid, zoals benadrukt werd door Bart Pattyn. Dit is uiteraard geen moreel neutrale positie. Neen, het is een moreel onhoudbare positie. Vergeleken met alle andere ambtenaren, of dat nu brandweerlui, belastinginners, rechters of sociaal werkers zijn, lijkt er in dit opzicht aan ons, leerkrachten - van de kleuterschool tot en met de doctoraatsprogramma's - iets heel speciaal te zijn dat ons een beetje zoals oudere broers en zussen maakt ten opzichte van onze studenten. We zijn onvermijdelijk en eindeloos bezig met hen te helpen opgroeien, en het aanleren van gezonde waarden is een deel van opgroeien.

Natuurlijk kunnen de meest directe en voor de hand liggende manieren om te onderwijzen wat wij geloven dat gezonde waarden zijn, gemakkelijk contraproductief werken. Toen ik student was aan het Filosofie Instituut van de UCL, hadden we een vak 'Vraagstukken uit de Bijzondere Moraalfilosofie' dat zo erg rook naar morele indoctrinatie dat we campagne voerden om het van het curriculum te schrappen. We faalden jammerlijk. Vijftien jaar later werd ik zelf aangesteld om dit vak te geven. Het zal u niet verbazen dat ik het zo snel mogelijk grondig hervormde om studenten aan te moedigen voor zichzelf te denken, en dat ik het, na de oprichting van de Hoover Leerstoel, herdoopte tot 'Sociale en Economische Ethiek'. Nu ik dat vak twee decennia gegeven heb, begin ik me echter schoorvoetend te realiseren dat het 


\section{(}

kernidee van de 'Vraagstukken uit de Bijzondere Moraalfilosofie' die ik geschrapt wou, zinvoller was dan ik dacht: het kernidee dat morele opvoeding een onderdeel is van wat we aan onze studenten verplicht zijn.

Natuurlijk kunnen we in de wereld van onze studenten deze taak niet volbrengen door hen een soort catechismus te laten leren of door een index van verboden auteurs of werken op te stellen. Integendeel, studenten zouden in contact moeten gebracht worden met de meest diverse, zelfs de meest extreme posities, hoe politiek incorrect ook, en discussiëren met mensen die hen vasthouden. Effectief moreel onderwijs kan en mag niet bouwen op een soort cordon sanitair de la parole. Als er effectief moreel onderwijs kan bestaan, zal het zijn omdat we niet terugschrikken voor het tactvol maar vastberaden uitdrukken van onze eigen morele overtuigingen, als en wanneer de gelegenheid zich voordoet; omdat we leven naar de overtuigingen die we verkondigen in het (gewoonlijk kleine) deel van ons leven dat de studenten delen; omdat we gelegenheden scheppen waar studenten de personen die we zelf bewonderen om hun intellectuele kwaliteiten maar ook om hun morele engagementen, kunnen ontmoeten en met hen kunnen interageren.

Dit is dan de tweede en niet zo gemakkelijke (en niet zo onomstreden) zin waarin het me onvermijdelijk en juist lijkt voor universiteiten om hun studenten te onderwijzen wat goed en fout is. Niet alleen scheppen de beslissingen van universiteiten collectief een waardegeladen en waardescheppende omgeving. Ieder van ons moet zich bovendien zelf bewust zijn van de morele opvoedingscomponent van zijn of haar rol. Voor de jonge volwassenen die aan ons toevertrouwd worden, zijn we niet alleen overdragers van kennis en onderwijzers van vaardigheden. We zijn ook zoiets als oudere broers en zussen, die hun boekje niet te buiten gaan wanneer ze in woord en daad, discreet in plaats van plechtig, een bepaalde opvatting van wat een goed leven uitmaakt, uitdrukken.

Het erkennen van de legitimiteit en het belang van deze taak brengt een aantal lastige vragen boven. Sommige daarvan hebben te maken met de inhoud van de waarden die het object van deze (meestal impliciete) morele opvoeding zouden moeten zijn. Andere vragen hebben te maken met de institutionele implicaties van het erkennen van de legitimiteit hiervan. Het blijft duidelijk dat de evaluatie van onze studenten, of ze slagen of falen en welk cijfer ze krijgen, alleen gebaseerd mag blijven op de kennis en vaardigheden die ze kunnen tonen en niet op hun savoir-être, hun morele engagementen en gedrag. Maar als morele opvoeding een deel van de taak van een universitaire docent is, blijft het dan even duidelijk dat de morele kwaliteiten van kandidaten principieel buiten beschouwing moeten blijven bij een aanstelling, of bij het 


\section{bespreken van promoties? Dit is een van de vele vragen waar ons zesde Ethische Forum ons mee confronteerde, zonder een definitief antwoord te geven...}

\section{Noten}

1. Het zesde Ethisch Forum van de Universitaire Stichting, "Is it wrong to teach what is right and wrong?", ging door op 29 november 2007 in Brussel. Deze tekst, uit het Engels vertaald door Veerle Achten, is een herwerkte en uitgebreide versie van de eindopmerkingen op het Forum en vooral gebaseerd op de lezingen die het Forum zijn inhoud gaven en op de discussie die daaruit voortkwam. Deze lezingen werden gehouden door Andris BARBLAN (algemeen secretaris van de Magna Charta Observatory on the Universities' Fundamental Values and Rights, in Bologna, en voormalig secretaris-generaal van de European University Association), Jean-Pierre RICHER (Université du Québec in Montréal), Emmanuelle Danblon (ULB), Bart PATTYN (K.U.Leuven), Robert Rubens (UGent), Yves Thiran (RTBf en UCL), Nigel Roome (ULB en Universiteit Tilburg) en Boudewijn BouckaerT (UGent). De diepgaande lezingen en de levendige debatten die eruit voortkwamen waren uiteraard veel rijker dan wat kon worden verwerkt of zelfs aangeraakt in deze opmerkingen. Ook willen deze opmerkingen geen consensus weergeven tussen de deelnemers. Integendeel, ik heb geprobeerd om te verzamelen wat ik zelf geleerd heb van en dankzij enkele van de lezingen, om zo mijn eigen visies op de thema's die het meest omstreden leken, vorm te geven, te veranderen of te verfijnen. Een samenvatting van de meeste lezingen is beschikbaar in het Engels op www.fondationuniversitaire.be/en/forum.php.

2. J. BRICMOnt. "Pourquoi nous ne sommes plus catholiques" Dossier ULB-UCL même combat? Bulletin du Cercle du libre examen 42 (2006): 15-18. Vertaling door Veerle Achten.

3. 10 mei 1985, zoals geciteerd door Bart PatTYN. "Het Debat aan de K.U.Leuven". www.fondationuniversitaire.be/en.forum6.php.

4. De verantwoordelijkheid van academici in het publieke debat was het onderwerp van ons derde Ethische Forum, "Free to Speak Out?", in november 2004. Voor een samenvatting in het Engels, zie www.fondationuniversitaire.be/common_docs/2004.SynthesisEF31.pdf. 